\title{
An Assessment of Both Patients and Medical Staff Awareness of the Risks of Ionizing Radiation from CT Scan in Cameroon
}

\author{
Mathurin Neossi Guena1,2, Daniel Ngalaleu Nguemeleu1, Thierry Ndzana Ndah ${ }^{3}$, \\ Boniface Moifo 4 \\ ${ }^{1}$ Departement of Biomedical Sciences, University of Ngaoundere, Ngaoundere, Cameroon \\ ${ }^{2}$ Radiology Department, Ngaoundere Regional Hospital, Ngaoundere, Cameroon \\ ${ }^{3}$ National Radiation Protection Agency (ANRP), Yaoundé, Cameroon \\ ${ }^{4}$ Département of Radiology and Radiation Oncology, Faculty of Medicine and Biomedical Sciences, University of de Yaoundé I, \\ Yaoundé, Cameroon \\ Email:mneossiguena@yahoo.fr, danielngalaleu@yahoo.fr, ndzanathierry@yahoo.fr, bmoifo@yahoo.fr
}

How to cite this paper: Guena, M.N., Nguemeleu, D.N., Ndah, T.N. and Moifo, B. (2017) An Assessment of Both Patients and Medical Staff Awareness of the Risks of Ionizing Radiation from CT Scan in Cameroon. Open Journal of Radiology, 7, 199-208.

https://doi.org/10.4236/ojrad.2017.73022

Received: July 21, 2017

Accepted: September 16, 2017

Published: September 19, 2017

Copyright $\odot 2017$ by authors and Scientific Research Publishing Inc. This work is licensed under the Creative Commons Attribution International License (CC BY 4.0).

http://creativecommons.org/licenses/by/4.0/

\begin{abstract}
Objectives: To assess the patients and health personnel's level of awareness on risks related to ionizing radiation during CT scan. Materials and methods: Three questionnaires were addressed to patients, prescribing physicians, and the medical imaging staff for three hospitals respectively. This permitted us to assess their knowledge on the benefits and risks of the required medical exam, based on the dangers of being exposed to X-rays, especially induced-radiation cancer following the amount of X-rays received during a CT scan and the possibility of not receiving radiation as tools of diagnosis. Results: 150 patients, 84 referring doctors of CT scan tests and 60 medical imaging personnel were retained. For patients, only $7.1 \%$ received information on the benefits and risks of their exams, and $34.4 \%$ believed that $\mathrm{x}$-rays were harmful to their health. For the prescribers, $46.7 \%$ took into account the benefits/risk ratio before prescribing a test and only $16.7 \%$ of the referring doctors have informed the patient of the risks related to X-ray. $90 \%$ of the medical imaging staff ensures that the required test is justified, and $50 \%$ informed the patient on the risks associated with their radiation exposure, and the increased risk of developing cancer. $65 \%$ of the imaging staff could not estimate the dose that the patient will receive during the medical test. $25 \%$ mentioned the dose received during the acquisition in the patient's exam report. Conclusion: This study confirms that the referring doctors, the patients, and the radiologists have a low knowledge concerning the risks associated with radiation exposure during a CT scan assessment. We will therefore say that
\end{abstract}


patients and prescribers are not aware of the doses of radiation on CT and their possible risks, even though there is a risk of developing cancer.

\section{Keywords}

X-Rays, CT Scan, Level of Knowledge, Risks, Patients, Medical Staff

\section{Introduction}

Since their discovery, X-rays have constantly contributed to revolutionizing in the medical fields by saving lives on daily basis [1]. They are mostly used in two procedures of medical imaging: radiography and Computed Tomography or Scanner. They occupy such an important place today that they have become an indispensable tool in medical diagnosis. However, this practice is not risk free. $\mathrm{X}$-ray is an ionizing radiation and therefore capable of causing harmful effects to tissues, depending on the dose received [2]. CT scan has particularly become a subject of interest since it constitutes the main source of exposure to X-ray [3] and also for the fact that the dose absorbed by an organ during a CT scan is one hundred times greater than that of a corresponding conventional radiography [4], hence considerable. It has recently been revealed in modern literature that there is an ever-increasing abuse in the use of these medical imaging methods [5], and most often in conditions that do not comply with employment standards.

Studies have shown that an uncontrolled use of ionizing radiation is likely to be due to an underestimation of the doses delivered and the risks associated with low doses of X-rays by prescribers [6] and the ignorance of the imaging personnel concerning the Doses of radiation received by patients during radiology diagnostic tests [7]; but also to the ignorance of the effects of ionizing radiation by the patients themselves [8]. What about the situation in sub-Saharan Africa? It is clear that there is a little vagueness in the assessment of risks to patients in sub-Saharan Africa in the face of new uses of X-rays and the level of awareness of their users elucidates this mystery [9].

Our objective was to assess the level of knowledge of patients, prescribers and imaging staff on the risks associated with irradiation doses during CT scan.

\section{Materials and Methods}

The study was carried out in the medical imaging services of three (3) hospitals structures, From March to November 2016.

\section{Participants}

Our target population was divided into three groups: 18 years old patients, who came to undergo a CT scan within the imaging department, from referring physicians requesting CT scan during the period of study; and all medical imaging 
personnel directly or indirectly involved in the realization and reading of the $\mathrm{x}$-rays examinations. Three questionnaires were designed for this purpose. They were given to the three groups respectively (patients, prescribing physicians, medical imaging personnel), and the identity of each participant was kept secret. They had three objectives: to assess their knowledge of the benefits and risks of the examination requested; to assess their knowledge on the dangers of X-rays especially the risk of induced-radiation cancer due to the dose received during the CT scan examination; The radiation protection measures adopted and the possibility of a non-irradiation examination. The interviews were in the form of multiple choice questions with a unique answer, where the interviewees had to tick the correct answer; equally with open-ended questions where participants could express themselves freely.

\section{Evaluation of Participants}

The imaging services were used to record the answers of patients and the imaging personnel. The other participants (prescribing physicians) were interviewed in their respective departments. We approached each participant after the CT scan. The subject and purpose of the study was presented to each person either verbally or in written form in order to seek for their consent. The data was collected from the patient who agreed to participate in the study and also from all medical staff: physician (residents/holders), radiologists (physicians, residents, technicians) directly involved in the health care of the patients under study. Each questionnaire handed out, was completed with the assistance of an investigator. To avoid favoritism, the questionnaires were handed over without prior preparation, to the participants, based on the subject matter.

The data collected were as follows:

At the level of the patient: Demographic data (gender, age, level of education, profession); Information on advantages and risks received prior to and after his examination (type, place of information); information on irradiation dose; knowledge of X-rays and their effects, the possibility of a non-irradiating substitute exam.

At the level of participants and medical imaging personnel: Demographic data (professional category, years of experience); the information given to the patient concerning his/her examination (risks, advantages, dose), they estimate on the dose of irradiation in CT and their knowledge on the X-rays.

Regarding the dose estimates for each CT acquisition, we find the dose length product (DLP) received by the patient during cerebral CT scan, abdominal-pelvic, lumbar and thoracic CT examinations. It was shown on the scanner console (GE Medical Systems) after the exams. For patients examined with the HITACHI brand device, the PDL was raised during the course of the examination. In the case of multiple exposures the PDL recorded in the same region was the sum of PDLs (as required by Decree 1151 of 11 June 2013 of the Ministry of Public Health of the Republic of Cameroon concerning dosimetry information 
to be included in the medical record). The effective dose (E) expressed in millisieverts $(\mathrm{mSv})$ was then calculated using the tissue conversion coefficient $(\mathrm{k}) \mathrm{ac}$ cording to the formula: $\mathrm{E}=\mathrm{PDL} \times \mathrm{k}$.

On each device, we were interested in the following parameters: $\mathrm{kV}$ and $\mathrm{mAs}$; The Pitch; The height of acquisition; the thickness of the sections; the speed of rotation. To collect the data we used: data sheets of A4 paper formats, and pens.

\section{Data Analysis}

The data collected from the questionnaires were transferred to an Excel 8.0 file and then coded and exported to the SPSS software and Epi info 7 for analysis. The discrete variables are presented as a series of (effective) quotations, and as percentages.

Dose and risk information were obtained from the website of the Institute for Radiation Protection and Nuclear Safety (IRSN). Data on radiation protection regulations in Cameroon were collected from the ANRP.

Averages and frequencies were compared using the Fisher test (frequencies) and the Kruskal and Wallis test (average). The margin of significance of the statistical tests was fixed at a $\mathrm{p}<0.005$ (confidence interval 95\%).

\section{Results}

\subsection{Evaluation of Patients}

150 patients met our selection criteria. The age groups varied from 20 to 85 years with an average of 46.67 years. The most widely represented age groups are those between the ages of 40 to 50 and 50 to 60 , with a proportion of $24.0 \%$. The most represented level of study was the university level with an average of $37.1 \%$, and they have the best answers amongst all the other participants.

Figure 1 shows that $72.86 \%$ of the patients received information based on their examination. Most of the information received from this group about the benefits of the examination (60.0\%), some during the clinical consultation, and others by their personal investigations.

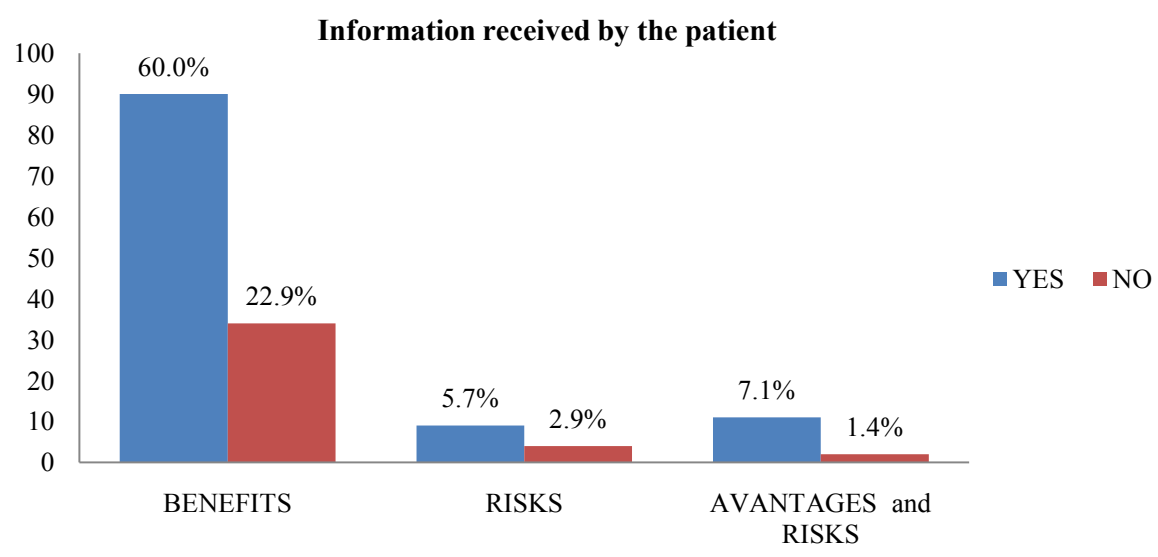

Figure 1. Different information's received by the patient. 


\subsection{Information Received by the Patient}

According to Table 1, 17.1\% believed that their risk of developing cancer increased following the medical examination. The irradiation dose was not reported to any patient after the CT scan.

\subsection{Effects of X-Rays on Health}

$38.6 \%$ of our patients had never heard of X-rays; but most of them (58.5\%) attributed the dangerous term to the $\mathrm{x}$-rays.

\subsection{Evaluation of Referring Doctors}

Eighty four questionnaires were collected and analyzed from prescribers. They were $53 \%$ composed of specialists, followed by general practitioners $40 \%$. Their years of experience varied from 1 to 26 years, with an average of 9.83 years. The most represented group was between 10 and 15 years of age. Most of them, $71.9 \%$, had received training in the radiation protection of patients during their training. For our referring doctors, $46.7 \%$ take into account the advantage/risk ratio before prescribing an examination. We found no link between this results and the radiation protection training. In addition, only $16.7 \%$ informed systematically the patient of the risks related to X-rays resulting from the examination, as compared to $40 \%$ (who often make mention of these risks; While $63.3 \%$ of prescribers believed that the risk of developing cancer may increase as a result of a CT scan. The prescribers were split into two groups according to their years of experience (level): a group of less than 10 years and a group of 10 years or more. The group of 10 years and above, informed the patients more of the risks associated with his/her examination. But the difference in distribution between the two classes is insignificant. None of the two groups informs the patient about the dose that they could receive during their CT scan, and none could estimate the dose of radiation that could be received by the patient during an abdominal pelvic CT scan. $32.3 \%$ of prescribers gave an exact dose ratio between a Chest $\mathrm{X}$-ray (RT) and an abdominal pelvic (CT) scan. It is more represented by the group of less than 10 years.

\subsection{Evaluation of Medical Imaging Staffs}

Sixty medical imaging personnel participated in this study. They were made up

Table 1. Health effects of X-rays.

\begin{tabular}{ccc}
\hline & Headcount & Percentage \\
\hline No replies & 58 & $38.6 \%$ \\
Destroying the cells & 51 & $34.3 \%$ \\
Cause cancer & 26 & $17.1 \%$ \\
Can reduce life span & 11 & $7.1 \%$ \\
none & 4 & $2.9 \%$ \\
TOTAL & 150 & $100 \%$ \\
\hline
\end{tabular}


of radiologists (35\%) and technicians (55\%), respectively. Resident Radiologists were poorly represented. Their years of experience varied from 2 to 26 years, with an average of 10.65 years. The most represented group was that of 5 and less years of experience. $75.0 \%$ have already received training in radiation protection. $90.0 \%$ of the imaging personnel ensure that the requested examination is justified. $50 \%$ of the imaging personnel informed the patient of the risks associated with their examination. Only $25 \%$ of the medical imaging personnel reported the dose received to the patient. $50 \%$ of the imaging staffs believed that the risk of developing cancer in the patient has increased. $65 \%$ of the imaging staffs could not estimate the dose that the patient will receive during the examination.

\section{Discussion}

The main objective of this study is to assess the level of awareness of patients, CT scan prescribers and medical imaging staffs regarding their knowledge of radiation doses during a CT scan and the possible risks. These participants were taken from three hospitals, with the background of the type of structures (public, private) their high-quality technical platform and their high level of attendance, to study the 'context' parameter in the patient-medical staff relationship. This was not the case in the study by Christophe I. Lee et al. [10]. We have encountered two limitations in our study: the poor knowledge of our different patients, the failure of radiation protection regulations and the non-application of existing laws.

\subsection{Characteristics of the Sample}

We sampled 150 patients for CT exams. We found neither correlation between the responses to the questions and the sex of the patients, nor between their age and their level of consciousness. $37 \%$ of our patients had a higher level of education; we found that this parameter could play a big role on the level of understanding of the investigator and his degree of involvement in the management of his pathology [11]. We interviewed each of them. An interview was preferable due to the lack of understanding of certain information in the questionnaire, such as the radiation dose, their X-ray representation, the name or type of examination requested. Nevertheless, we have noted that a high level of study in our context, increases the level of knowledge of the patients on the $\mathrm{x}$-ray, but does not help to raise their level of consciousness regarding the $\mathrm{x}$-ray and the possible risks involved; Since none of them had asked the prescriber for a non-irradiating examination.

Seventy six (76) and sixty (60) questionnaires were recovered from the prescribers of CT scans and from the medical imaging staffs respectively. The percentage of filled forms stood at $91.1 \%$. However, we found that there is a weak correlation between the number of years of experience and the results of the working staffs $(\mathrm{F}$-test $=0.8123, \mathrm{p}=0.375)$. These finds disagree with those of 
Christoph I. Lee et al. [10], where years of experience increase the level of consciousness of this group. But agree with those of Moifo B. et al. in Cameroon [12], who found out that the level of unsatisfactory knowledge (79.5\%) among prescribing doctors regarding the justification of examinations as exposed to ionizing radiation. This may be related to the fact that in our context, health professionals do not benefit from any continuous training organized in radiology protection hospitals as Daniel Zewdneh et al. discovered [13].

\subsection{Information on the Benefits and Risks of the Exam}

$27.2 \%$ of our patients had not received any information regarding the risks or benefits arising from their CT scan. And $60 \%$ had received some basic information concerning the benefits of the examination. Only $7.1 \%$ received information about the benefits and risks of their examination and 5, 9\% only on the risks (Figure 1). Gervaise AF et al., Confirms that the practitioner must emphasize on the expected benefit of the examination and the resulting benefit/risk relationship [14]. These patients received information about the risks involved in their personal research. Our data confirms, as in other studies, that this information is poorly communicated [10] [14]. 46.7\% of the prescribers take the benefit/risk ratio into account before prescribing an examination, and only $33.33 \%$ inform the patient of the risks associated with the examination.

It should be noted that $85 \%$ of the medical imaging staffs do not know if the patient has been informed of the risks associated with their examination. Majority ( $\mathrm{p}=80 \%$ ) of the prescribers declared that due to insufficient time, they were unable to adequately inform the patient about the risks of their examination, except for more matured patients to whom they mentioned the benefits of the examination. Leclere J. et al. Went on to show that the desire of the medical staff to inform the patients also depended on their personality, their involvement in the relationship, their ability to listen and their mood at the time, his level of tiredness or stress [11].

\subsection{Risk of Radiation-Induced Cancer}

A lesser amount (17.1\%) of patients felt that their risk of developing cancer as a result of their CT scan had increased as reported in Table 1. But most (65.7\%) had no idea on this issue. On the side of the medical staffs, we observed the opposite, where $63.3 \%$ of the prescribers and $50 \%$ of the medical imaging staffs thought that the risk of cancer patients could increase further due to a CT scan. The disproportion of opinion among radiologists and prescribers suggests that concrete information about the possible risks of radiation - induced cancer is not controlled by the medical profession.

\subsection{Information on Irradiation and Dose Estimation}

The average doses delivered during an abdominal pelvic CT scan were: 30.67 $\mathrm{mSv}$ and that of a CT scan was: $20.46 \mathrm{mSv}$. These values are higher than those of 
the diagnostic reference levels established by the IRSN [15]. The International Commission on Radiological Protection (ICRP) certifies that: The average risk of cancer death in a Western society is about $25 \%$. After a CT scan involving 10 $\mathrm{mSv}$ irradiation, this risk is increasing by only $0.05 \%$ (hence $25.05 \%$ ) [16].

There is therefore a risk of developing cancer following CT examinations. In fact, most of our patients $(\mathrm{p}=35.71 \%, \mathrm{n}=25$ ) had received doses greater than $10 \mathrm{mSv}$. However, almost all (100\%) of our patients were not informed about the dose of irradiation received during the CT scan and the possible risks involved. However, the regulations of the Republic of Cameroon require that the dose (DLP) received during the exam should be mentioned on the patient's report and that the latter should be informed [17]. Most referring doctors stated that the imaging staffs responsible for irradiation should inform the patient of the risks involved. Some authors have suggested that the referring doctor, rather than the radiologist or technician or radiographer, is the most appropriate person to discuss these issues because they are more intimately acquainted with the clinical details of the patient and the need for a particular examination [18]. This lack of information revealed that the prescribers and the imaging staffs interviewed had little or no knowledge of the doses of irradiation; If they do not inform the patient, it is because they have no knowledge of the possible doses of irradiation in the scanner. $46.66 \%$ of the prescribers underestimated the dose ratio between a Chest X-ray (RT) and an abdominal pelvic (CT). This was also the case in Jacob K and al [18]. From these findings and those mentioned above, it can be said that the level of knowledge of prescribers and patients about the risks associated with scanning is very low.

We noted that $90 \%$ of our patients arrived in our imaging services at least one day after the consultation. Some arrived at the hospital already worried and having preconceptions about the examination they will undergo from their knowledge acquired at school on x-rays (48.6\%) and from public opinion they know on scanning. Most $(60.00 \%)$ of our participants who had heard of X-rays believed that X-rays can destroy their cells thus reducing their lifespan and can be the cause of cancer; It should be noted that $64.28 \%$ of them did not know that their exam required the X-rays. These reports show us an alarming state of the adequate information to patients in medical imaging services.

\subsection{Limitations of Our Study}

Our study is limited by the fact that we cannot investigate all the public's awareness of the risks associated with $\mathrm{x}$-rays. It was limited to hospitals. We had not studied consciousness on the induction of mutations by $\mathrm{x}$-rays because these link to the cancer development. There are also other risks in hospitals, particularly in imaging departments, such as the risk of reaction to contrast media, for which awareness of patients and medical staff can also be studied.

\section{Conclusions}

Our study confirmed the low level of knowledge of referring physicians and pa- 
tients, moderate level of knowledge of radiologist regarding the risks associated with irradiation during a CT scan. We will therefore say they are not aware of the doses of irradiation on CT scan and their possible risks, even though there is a risk of developing cancer.

All these data therefore seek to encourage the principle of precaution, without overestimating the risks of radiation-induced cancer associated with low doses of $\mathrm{X}$-rays. The practice of informing patients on the risks of their examination and the routine transcription of dosage information on their reports will permit us to situate our practices and to adapt them in relation to the values of the reference guides.

\section{Acknowledgements}

For the staff members of Yaounde Central Hospital, Centre Medical la Cathedrale and Bafoussam Regional Hospital.

\section{Conflict of Interest}

The authors declare that they have no conflict of interest in relation to this article.

\section{References}

[1] Les Rayons, X. Une révolution dans l'avancée du diagnostic médical. Risques et limites.

http://tperayonsxjf.e-monsite.com/pages/iii-interets-et-limites/b-risques-et-limites. html

[2] Fazel, R., Krumholz, H.M., Wang, Y.F., Ross, J.S., Chen, J., Ting, H.H., Shah, N.D., Nasir, K. and Einstein, A.J. (2009) Exposure to Low-Dose Ionizing Radiation from Medical Imaging Procedures. The New England Journal of Medicine, 361, 849-857. https://doi.org/10.1056/NEJMoa0901249

[3] Etard, C., Sinno-Tellier, S. and Aubert, B. (2010) Exposition de la population francaise aux rayonnements ionisants liée aux actes de diagnostic médical en 2007. Rapport conjoint IRSN.

[4] Comité scientifique des Nations Unies pour l'étude des effets des rayonnements ionisants. (2010) Sources and Effects of Ionizing Radiation, in rapport UNSCEAR 2008. New York.

[5] Brenner, D.J. and Hall, E.J. (2007) Computed Tomography: An Increasing Source of Radiation Exposure. The New England Journal of Medicine, 357, 2277-2284. https://doi.org/10.1056/NEJMra072149

[6] Krille, L., Hammer, G.P., Merzenich, H. and Zeeb, H. (2010) Systematic Review on Physician'S knowledge about Radiation Doses and Radiation Risks of Computed Tomography. European Journal of Radiology, 76, 36-41. https://doi.org/10.1016/j.ejrad.2010.08.025

[7] Shiralkar, S., Rennie, A., Snow, M., Galland, R.B., Lewis, M.H. and Gower-Thomas, K. (2003) Doctors' Knowledge of Radiation Exposures Is Deficient. BMJ, 324, 919.

[8] Société Française de Radiologie. (2010) Les rayonnements ionisants et leurs applicaions médicales, fiche information patient, septembre. http://www.sfrnet.org/

[9] Wamba, A. (2014) Reconnaître pour choisir, orienter et rencontrer. Mères, guéris- 
seurs et biomédecins à l'épreuve des rencontres et reconnaissances en milieux pédiatriques camerounais., in Anthropologie. Université de Montréal, papyrus.bib.umontreal, p. 329.

[10] Lee, C.I., Haims, A.H., Monico, E.P., Brink, J.A. and Forman, H.P. (2004) Diagnostic CT Scans: Assessment of Patient, Physician, and Radiologist Awareness of Radiation Dose and Possible Risks. Radiology Health Policy and Practice, 231, 393-398.

[11] Leclere, J., Ollivier, L., Dolbeault, S. and Neuenschwander, S. (2006) Dialogue entre le radiologue et le patient atteint d'un cancer. Journal of Radiology, 87, 99-104.

[12] Moifo, B., Edzimbi, A., Haoua, T., Joshua, T., Richard, S. and Gonsu, J. (2014) Referring Physicians' Knowledge on Justification of Medical Exposure in Diagnostic Imaging in a Sub-Saharan African Country, Cameroon. Open Journal of Radiology, 4.

[13] Zewdneh, D., Dellie, S.T. and Ayele, T. (2012) A Study of Knowledge \& Awareness of Medical Doctors towards Radiation Exposure Risk at Tikur Anbessa Specialized Referral and Teaching Hospital, Addis Ababa, Ethiopia. IOSR Journal of Pharmacy and Biological Sciences, 2, 1-5. https://doi.org/10.9790/3008-0240105

[14] Gervaise, A., Esperabe-Vignau, F., Pernin, M., Naulet, P. and Porton, Y. (2011) Lapierre-Combes. Évaluation des connaissances des prescripteurs de scanner en matière de radioprotection des patients. Journal de Radiologie, 92, 681-687.

[15] Roch, P., Talbot, A., Rehel, J.L. and Aubert, B. (2009) Bilan 2007-2008 des niveaux de reference diagnostiques en scanographie. Journal de Radiologie, 90, 1258.

[16] Montag, B. (2010) Guide pratique pour la réduction de dose. Siemens Healthcare, CEO Imaging \& Therapy Systems.

[17] CAMEROON (2013) Le Ministère de la Santé Publique, Arrêté n 1151/A/MINSANTE du 11 juin 2013 fixant les modalités de suivit médical et dosimétrique des travailleurs et des patients exposés aux rayonnements ionisants. art13 and 17.

[18] Jacob, K., Vivian, G. and Steel, J.R. (2004) X-Ray Dose Training: Are We Exposed to Enough? Clinical Radiology, 59, 928-934.

\author{
Abbreviations Note \\ CT: Computed Tomography \\ mAs: Milli ampere seconds \\ DLP: Dose Length Product \\ GE: General electric \\ Kv: Kilo voltage \\ mSv: milli Siervet \\ ICRP: International Commission on Radiological Protection \\ IRSN: Institute of Radiation Protection and Nuclear Safety
}


Submit or recommend next manuscript to SCIRP and we will provide best service for you:

Accepting pre-submission inquiries through Email, Facebook, LinkedIn, Twitter, etc. A wide selection of journals (inclusive of 9 subjects, more than 200 journals)

Providing 24-hour high-quality service

User-friendly online submission system

Fair and swift peer-review system

Efficient typesetting and proofreading procedure

Display of the result of downloads and visits, as well as the number of cited articles Maximum dissemination of your research work

Submit your manuscript at: http://papersubmission.scirp.org/

Or contact ojrad@scirp.org 